\title{
Erratum to: Differences in expression of proliferation-associated genes and $R A N K L$ across the menstrual cycle in estrogen receptor-positive primary breast cancer
}

\author{
Ben P. Haynes • Giuseppe Viale • Viviana Galimberti • \\ Nicole Rotmensz • Bianca Gibelli • Ian E. Smith • \\ Mitch Dowsett
}

Published online: 26 November 2014

(C) Springer Science+Business Media New York 2014

Erratum to: Breast Cancer Res Treat (2014)

148:327-335

DOI 10.1007/s10549-014-3181-6

In the original publication of the article, Fig. 3 was mislabelled as Fig. 4 and vice-versa. This means that references to these figures in the text are the wrong way round.

The online version of the original article can be found under doi:10.1007/s10549-014-3181-6.

B. P. Haynes $(\bowtie) \cdot$ M. Dowsett

Department of Academic Biochemistry, Royal Marsden

Hospital, Fulham Road, London SW3 6JJ, UK

e-mail: ben.haynes@icr.ac.uk

G. Viale

University of Milan School of Medicine, Milan, Italy

G. Viale

Division of Pathology, European Institute of Oncology,

Milan, Italy

V. Galimberti

Division of Senology, European Institute of Oncology, Milan, Italy
N. Rotmensz

Division of Epidemiology and Biostatistics, European Institute of Oncology, Milan, Italy

B. Gibelli

Department of Head \& Neck Surgery, European Institute of Oncology, Milan, Italy

I. E. Smith

Department of Medicine, Royal Marsden Hospital, Fulham Road, London SW3 6JJ, UK

M. Dowsett

The Breakthrough Breast Cancer Centre, The Institute of Cancer Research, Fulham Road, London, UK 